\title{
O MERCADO DE TERRAS EM SÃO PAULO

\author{
e a CONTINUAda EXPANSÃo DA PERIFERIA
}

\author{
HAROLDO DA GAMA TORRES \\ RENATA GONÇALVES
}

R E S U M O Este artigo investiga aspectos da evolução da produção imobiliária habitacional formal na Região Metropolitana de São Paulo (RMSP) nos últimos quinze anos. A partir de uma breve reflexão sobre a idéia de centralidade e da utilização de dados de lançamentos imobiliários (Embraesp), elabora-se um modelo de formação do preço da terra que evidencia a grande importância da localização geográfica do imóvel. Os dados apontam também para um incremento significativo do preço dos imóveis residenciais ao longo da década de 1990 nas áreas urbanas mais centrais, o que poderia, em parte, explicar o processo de esvaziamento demográfico do chamado "centro expandido" e a persistente expansão das áreas periféricas, uma vez que um número menor de moradores tem tido acesso às áreas centrais, mais valorizadas.

P A L A V R A S - C H A V E Mercado de Terras; segregação residencial; São Paulo; planejamento urbano e áreas metropolitanas.

\section{INTRODUÇÃO}

$\mathrm{Na}$ literatura sobre a questão urbana no Brasil, muitas vezes se tomou como um fato o nexo causal entre a dinâmica do mercado formal de terras e a expansão continuada das áreas periféricas. Considera-se que o elevado preço das terras localizadas nas áreas centrais e mais bem dotadas de infra-estrutura permitiria aos grupos de renda mais elevada monopolizar frações importantes do território das cidades brasileiras. ${ }^{1}$ Sobraria assim, aos grupos de menor renda, residir nas periferias distantes, menos dotadas de infra-estrutura, em soluções de moradia autoconstruídas e de baixo custo, freqüentemente localizadas em áreas de ocupação irregular. ${ }^{2}$

De acordo com esse argumento, a reduzida oferta de terras e o preço excessivamente elevado do solo urbano teriam contribuído para que grande parte da população, sem acesso ao mercado formal de habitação ou a alternativas públicas de provisão de habitação social, fosse levada a morar em regiōes desprezadas pelo mercado imobiliário formal, em áreas públicas, em locais nos quais a legislação restringia a ocupação, como as áreas de proteção ambiental. Maricato (1997), por exemplo, aponta que a regulação do acesso a terra se traduz em uma complexa legislação que contribuiu para a formação de um mercado imobiliário restrito e especulativo. O mercado imobiliário seria caracterizado como vetor responsável pela produção e reprodução da segregação residencial (Smolka, 1992) e, de maneira geral, não se interessaria em atender a maior parte da demanda por habitação, que não se configura como demanda solvável (Maricato, 1996). Assim, para as classes mais pobres, a forma de acesso ao solo urbano se daria essencialmente de maneira precária e ao largo da legislação existente.

1 Villaça (1998) aponta duas forças que influenciariam as estruturas urbanas: a localização dos bairros residenciais de alta renda e o desenho do sistema de transportes.

2 Vários autores abordaram a questão da iniqüidade de acesso e a diferenciação do uso e apropriação do solo urbano entre as distintas classes sociais. Ver, dentre eles: Maricato, 1996 e outros; Smolka, 1987 e outros; Bonduki e Rolnik, 1982. 
3 Tal perspectiva analítica tem por inspiração modelos de renda da terra de origem marxista.

40 texto de Smolka (1992) é uma importante exceção.
5 Em termos empíricos, podemos considerar tanto modelos com uma única centralidade, como com múltiplas centralidades. Discutiremos esse elemento mais à frente.

Embora essa literatura não ignore a relevância de aspectos propriamente urbanísticos - como os sistemas de transportes - e institucionais - como a regulação do uso e ocupação do solo - na configuração do chamado gradiente de terra urbano, há uma ênfase significativa atribuída ao papel da localização geográfica da moradia das famílias de alta renda como elemento central da lógica urbana. ${ }^{3}$ Boa parte dos estudos na área são ensaios, cuja base empírica fundamenta-se numa observação "impressionista" da distribuição do preço da terra nas diferentes áreas urbanas, bem como da distribuição dos grupos sociais no espaço. ${ }^{4}$ As hipóteses presentes nessa literatura estruturam um certo modo de pensar a cidade que teve grande impacto sobre toda uma geração de pensadores sobre a questão urbana no Brasil. Nesse sentido, o principal objetivo desse artigo é retornar a esses argumentos a partir de um novo conjunto de fontes de dados e de métodos estatísticos viabilizados pelo recurso aos modernos Sistemas de Informações Geográficas (SIG).

Pretendemos empreender essa reflexão a partir de três perspectivas principais. $\mathrm{Na}$ primeira Seção, refletimos sobre a idéia de centralidade, conceito essencial para operacionalização empírica de qualquer modelo de renda da terra. Na segunda Seção, buscamos testar até que ponto a idéia de distância em relação à centralidade pode ser utilizada, ou não, como variável explicativa principal para o preço da terra em São Paulo. Discutiremos tal argumento a partir de um modelo de regressão onde consideramos diferentes hipóteses alternativas. Na terceira Seção, buscamos avaliar a evolução temporal da distribuição espacial do preço da terra em São Paulo nos últimos vinte anos, procurando avaliar o impacto dessa dinâmica para a expansão da periferia metropolitana. Por fim, apresentamos algumas considerações finais, além de um anexo.

\section{EVOLUÇÃO DA CENTRALIDADE URBANA EM SÃo PAULO}

O conceito de centralidade urbana é polifônico, quando se refere, por exemplo, à localização das principais atividades econômicas, à localização dos serviços terciários sofisticados ou, ainda, à localização da moradia das famílias de alta renda. Segundo Frúgoli (2000), a realidade de uma metrópole como São Paulo seria marcada pela competição entre várias centralidades ou pólos. A força dessas centralidades em disputa dependeria dos investimentos e dos distintos intuitos de empresas, do poder público, de instituiçóes bancárias e dos grupos sociais nelas localizados. Dependeria, sobretudo, do dinamismo econômico e da força política desses atores sociais que se localizam e interferem em diferentes áreas da cidade, assim como de projetos e concepções urbanísticas que propõem visões divergentes a respeito da vida urbana, das relações sociais, do tipo de metrópole e de seus usos.

Em vista das complexidades envolvidas em tal definição, em vez de tomar algum marco urbano a priori - seja a Praça da Sé, a Avenida Paulista ou a Avenida Faria Lima como referência de centralidade urbana, trataremos a centralidade como uma categoria empírica, relacionada à distribuição do preço da terra na cidade. Na prática, buscaremos operacionalizar um indicador de centralidade que seja dinâmico, isto é, que varie ao longo do tempo e do espaço, refletindo, de certo modo, as disputas pela centralidade urbana mencionadas acima. ${ }^{5}$

Para uma aproximação da questão da centralidade urbana, apresentamos uma breve descrição da dinâmica espacial dos lançamentos imobiliários a partir de meados da déca- 
da de $1980 .{ }^{6} \mathrm{~A}$ idéia de utilizarmos lançamentos imobiliários como unidade de informação se justifica porque estamos preocupados com a dinâmica do mercado residencial e com seus impactos sobre a expansão periférica. ${ }^{7} \mathrm{Na}$ prática, embora a concentração espacial das atividades econômicas possa ter impacto significativo para a distribuição espacial do custo da moradia, as centralidades econômica e residencial estão fortemente imbricadas no caso de São Paulo, sendo que ambas convergiriam - segundo a literatura - para o chamado quadrante Sudoeste da cidade. ${ }^{8}$

Podemos observar no Mapa 1, a seguir, uma notável mudança no perfil de localização dos lançamentos imobiliários na Região Metropolitana de São Paulo. Esse mapa mostra a evolução da dinâmica espacial dos lançamentos imobiliários entre 1985 e 2003, tendo como referência o percentual da área construída na área de ponderação em relação ao total de área construída na região metropolitana no período. ${ }^{9}$ Para uma melhor observação espacial de tal dinâmica de expansão urbana, os lançamentos foram divididos em quatro períodos: 1985-1989; 1990-1994; 1995-1999 e 2000-2003.

Mapa 1 - Distribuição do percentual da área construída em lançamentos imobiliários segundo Áreas de Ponderação do Censo Demográfico. ${ }^{10}$ RMSP, 1985-2003
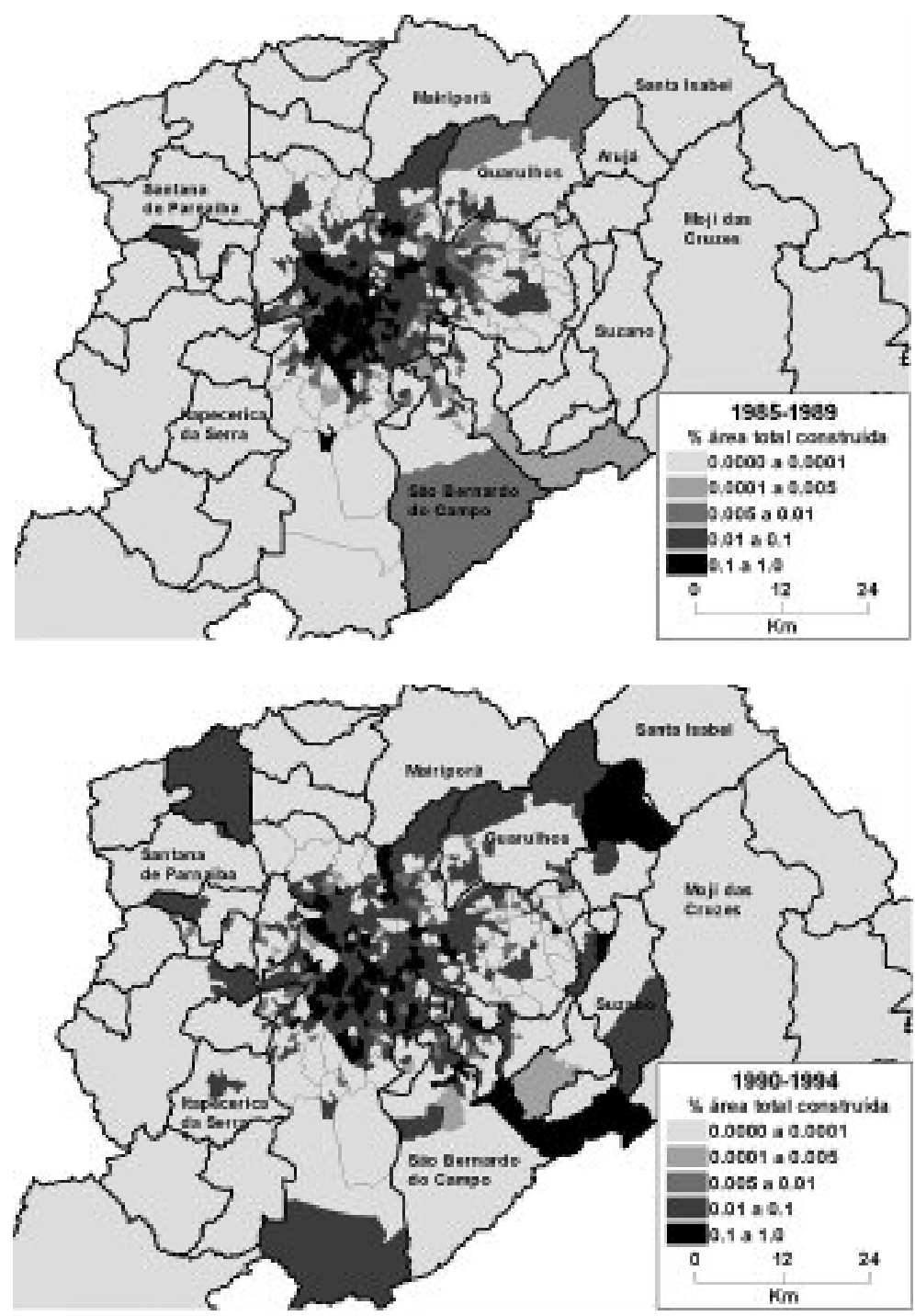

6 Utilizamos o banco de lancamentos imobiliários residenciais da Empresa Brasileira de Estudos do Patrimônio - Embraesp. As informações disponíveis no banco abarcam os empreendimentos imobiliários divulgados nos meios de comunicação de massa (jornais, revistas, panfletos, assim como os aprovados pela Secretaria da Habitação do MSP), lançados entre 1985 e 2003 na RMSP.

7 Os lançamentos constantes na base utilizada abrangem apenas uma parte da produção imobiliária residencial na metrópole. Destacase que o banco de registros da Embraesp não representa a totalidade do mercado residencial formal, sobretudo porque não abrange 0 mercado secundário, de compra e venda de imóveis usados, assim como, infelizmente, não dispomos de dados para outros tipos de habitação, tais como habitações autoconstruídas em favelas e loteamentos irregulares e outros tipos de autoconstrução, domicílios construídos por pequenas empresas, entre outros.

8 De todo modo, ambas as dimensões serão consideradas na análise realizada.

9 Escolhemos a área de ponderação como unidade de análise por ser uma unidade espacial mais homogênea que 0 distrito e mais abrangente que o setor censitário, o que nos permite evitar erros de geocodificação.

10 As Áreas de Ponderação correspondem à menor unidade geográfica para divulgação dos resultados da Amostra do Censo Demográfico do IBGE, na qual foram imputados os dados relativos à base de lançamentos imobiliários da Embraesp, uma base de pontos georreferenciados. 

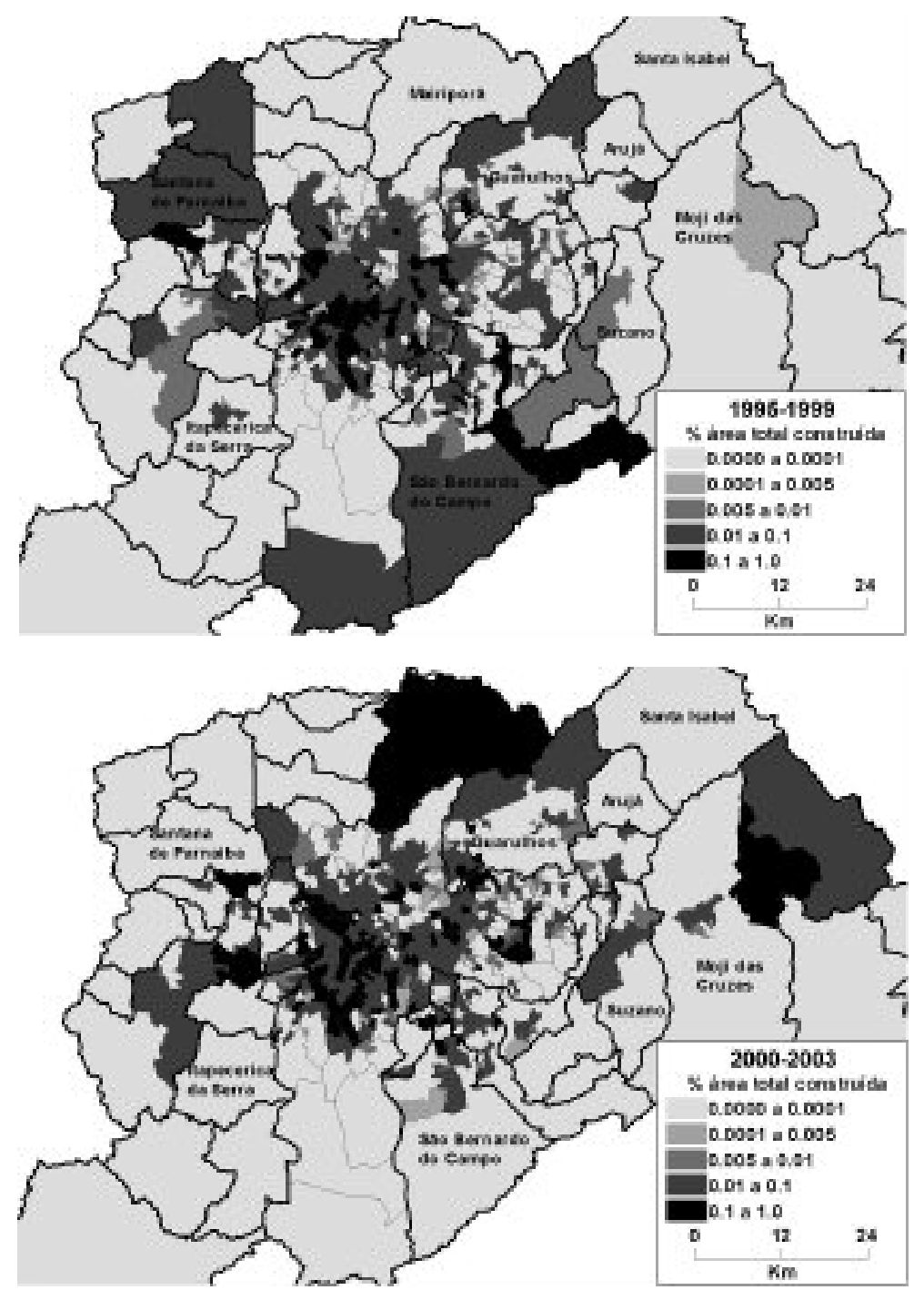

Fonte: Embraesp, 1985-2003.

Podemos constatar que as maiores proporções de lançamentos têm efetivamente se concentrado no setor sudoeste do Município de São Paulo - especialmente nos distritos do Morumbi, parte da Vila Andrade e de Santo Amaro, Itaim Bibi e Moema. Em outras palavras, esses dados não parecem sugerir, ao menos do ponto de vista dos lançamentos imobiliários, uma situação de múltiplas centralidades. Existe um núcleo central claro, embora ocorrências descontínuas importantes possam ser observadas nos distritos de Santana e Tatuapé e nos municípios do ABC, além do entorno de Barueri.

Vale observar, no entanto, que houve um notável espraiamento dos lançamentos imobiliários para outras áreas da cidade. De fato, constatamos, por um lado, um aumento importante na frequiência de lançamentos na direção noroeste (Lapa, Alto de Pinheiros, Vila Leopoldina). Notamos também, em certos períodos, uma expansão significativa do volume de lançamentos na Zona Leste de São Paulo e nos municípios do ABC.

Os dados espacializados evidenciam que houve uma expansão importante da área urbana relevante do ponto de vista do mercado imobiliário, argumento que já havia sido formulado anteriormente pela literatura (Marques, 2005). Enquanto, no passado, o setor privado da construção imobiliária - responsável pelos lançamentos imobiliários aqui con- 
siderados - concentrava fortemente esses lançamentos do ponto de vista espacial, observava-se claramente um processo de descentralização. Esse dado constitui uma primeira evidência relevante de que a centralidade do volume de lançamentos imobiliários residenciais poderia estar em movimento nesse período. ${ }^{11}$

Vale também notar que os lançamentos imobiliários não se expandem de forma regular para todo o entorno da área central. Se existem claramente áreas privilegiadas para a expansão desses lançamentos, como as mencionadas acima, parece também existirem barreiras espaciais significativas. Na verdade, como no caso de São Paulo as barreiras físicas são menos relevantes - a não ser no extremo norte e sul da região -, vale argumentar que as principais barreiras à expansão dos lançamentos imobiliários devem ter necessariamente um caráter sócio-urbanístico. Para refletir sobre esse argumento, apresentamos no Mapa 2 a distribuição desses lançamentos imobiliários sobreposta à localização de favelas, loteamentos irregulares e conjuntos habitacionais.

Mapa 2 - Distribuição espacial dos lançamentos imobiliários, favelas, loteamentos irregulares e conjuntos habitacionais. RMSP, 1985-2003

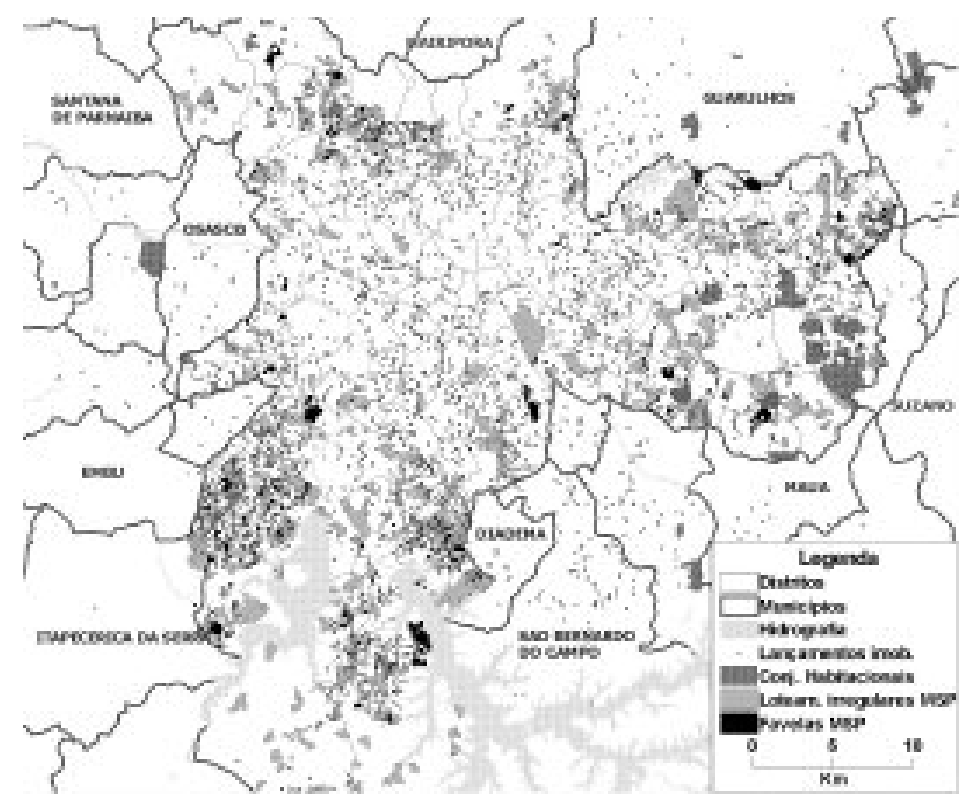

Nota: Os dados relativos a favelas e loteamentos irregulares se referem apenas ao MSP. Fontes: Embraesp e Sehab-PMSP.

De fato, podemos observar no Mapa 2 que os lançamentos imobiliários parecem contidos espacialmente ao sul, norte e leste do Município de São Paulo por uma presença significativa de áreas de moradia popular com regularização precária: favelas ou loteamentos. Tal distribuição implica que, embora o espraiamento mencionado anteriormente esteja efetivamente se verificando, os vetores desse espraiamento de certa maneira influenciam e são influenciados pela presença de bolsões de moradia irregular nos interstícios urbanos e periferias (Marques e Bitar, 2002; Smolka, 1992). Em outras palavras, a presença dessas barreiras também interfere na conformação da centralidade residencial, se as considerarmos como referência para análise dos lançamentos imobiliários.

Para avançar nessa discussão, adotamos uma aproximação empírica do conceito de centralidade a partir do chamado "centro de massa" dos lançamentos imobiliários produ-
11 Apesar de as periferias mais extremas serem marcadas, de modo geral, por baixa ou nenhuma atividade imobiliária, mesmo alojando aproximadamente metade da população metropolitana (Marques, 2005). 
12 Em termos matemáticos, o centro de massa adotado corresponde a: $\left\{\sum\right.$ (LAT ou LON * preço do $\left.\mathrm{m}^{2}\right) /$ $\sum$ preço do $\left.\mathrm{m}^{2}\right\}$; em que LAT e LON se referem à latitude e longitude do empreendimento em questão.

zidos no período analisado. $\mathrm{O}$ centro de massa aqui apresentado corresponde à localização geográfica média do conjunto de lançamentos para um dado período, ponderada pelo preço do metro quadrado dos lançamentos em questão. ${ }^{12}$

Em outras palavras, a centralidade, conforme aqui definida, é influenciada simultaneamente pelo volume de lançamentos imobiliários localizados em um dado local e pelo valor unitário desses lançamentos. Nesse sentido, se os preços da área construída fossem constantes em toda cidade, o centro de massa seria influenciado exclusivamente pela distribuição geométrica dos lançamentos na cidade. Como isso não acontece, as áreas com preços mais elevados "puxam" o centro de massa, mesmo quando não têm um volume de lançamentos muito expressivo.

A partir desse modelo de centralidade, podemos observar, no Mapa 3, a seguir, a localização do indicador de centro de massa para os quatro períodos considerados anteriormente.

Mapa 3 - Centro de Massa dos Lançamentos Imobiliários Residenciais em São Paulo, segundo período. RMSP, 1985-2003

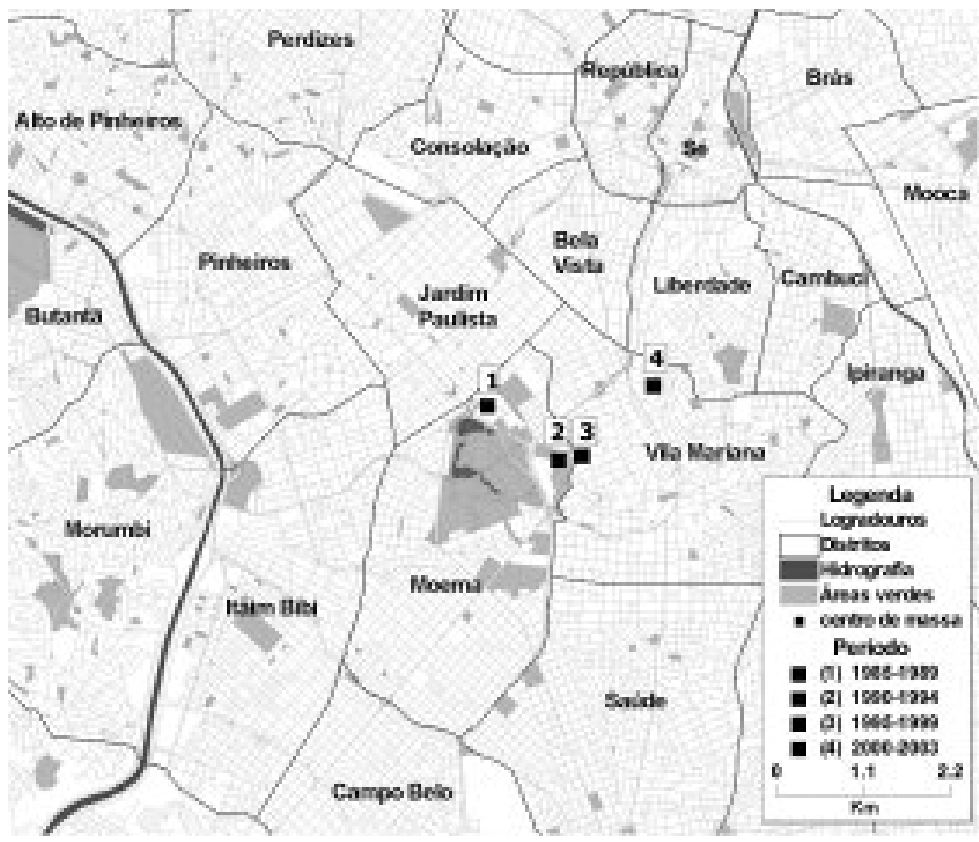

Fonte: Elaboração a partir de dados da Embraesp.

Essa evolução nos permite algumas observaçōes relevantes. Em primeiro lugar, a centralidade medida a partir do centro de massa corresponde, em grande medida, ao senso comum a respeito da dinâmica do mercado de terras. O centro de massas encontrava-se, nos quatro períodos, em locais próximos ao Parque do Ibirapuera, área nobre da cidade, com elevado valor da terra.

Em segundo lugar, essa centralidade variou pouco nos quatro períodos considerados. Embora tenha ocorrido o referido espraiamento dos lançamentos imobiliários, o centro geográfico desses lançamentos variou pouco, sugerindo que tais lançamentos estejam se espraiando de modo relativamente homogêneo para diferentes direçôes da cidade. No entanto, cabe também notar que houve um discreto deslocamento no centro de massa na direção leste. Em outras palavras, o volume de novos lançamentos na Zona Leste e no ABC 
parecem ter produzido algum deslocamento da centralidade na direção leste, sendo que o elevado preço dos imóveis no vetor sudoeste não contrabalançou esse efeito.

Evidentemente, um indicador desse tipo tem limitaçōes relevantes. Por exemplo, poderíamos - em vez de considerar o preço - construir um centro de massa referido ao número de unidades habitacionais lançadas ou à área total construída. Além disso, seria desejável obter dados que nos permitissem considerar todos os diferentes produtos imobiliários da cidade, em áreas regulares e irregulares. Apesar dessas limitações, o indicador aqui construído torna possível avaliar empiricamente os efeitos da localização do imóvel sobre seu preço, num modelo que também leva em conta outros possíveis determinantes. Detalhamos esses elementos a seguir.

\section{DETERMINANTES DO PREÇO DOS LANÇAMENTOS IMOBILIÁRIOS}

$\mathrm{Na}$ literatura brasileira e internacional, podemos encontrar um conjunto diversificado de hipóteses explicativas a respeito da formação do preço da moradia formal. Como mencionado, boa parte dos estudos urbanos brasileiros atribui importância central aos fatores de localização, embora aspectos como as formas de regulação do uso do solo (Maricato, 1997), o papel do Estado na provisão de infra-estrutura e serviços urbanos e a disputa pela apropriação dos bens e serviços coletivos (Vetter e Massena, 1981; Villaça, 1998), assim como aspectos relativos às demandas e à ação organizada dos capitais privados em busca de valorização (Ribeiro, 1997) também possam ser mencionados.

Vale notar que Smolka (1992) destaca que, embora por motivos diferentes, "as abordagens neoclássicas e clássico-marxistas (...) reconhecem o mercado imobiliário como instrumento eficaz, através do qual as acessibilidades (...) são 'discricionariamente' distribuídas”. De fato, na literatura de recorte mais neoclássico, argumentos análogos podem ser observados. Ao lado dos efeitos da localização e dos custos de transporte e mobilidade, também exercem papel importante na dinâmica desse mercado a presença de economias de aglomeração e alguns aspectos institucionais, relacionados a formas de regulação do uso da terra - tais como o zoneamento urbano, assim como os impostos imobiliários. O mercado influenciaria também nos fenômenos urbanos que parecem ter origem e caráter essencialmente sociais, como a expansão de favelas e periferias (Richardson, 1971). Outros autores destacam ainda o papel das preferências do consumidor por amenidades urbanas que, aliadas aos efeitos de localização e aos custos de transporte, induziriam à escolha, por exemplo, de imóveis em áreas próximas a parques urbanos (Henderson, 1988), e destaca-se ainda a atribuição de maior peso à capacidade financeira das famílias - reconhecendo-se que grupos sociais distintos têm preferências diferenciadas no consumo do espaço; grupos de mais alta renda, por exemplo, valorizariam uma certa forma de vida associada a baixas densidades demográficas e um consumo de uma grande quantidade de área (Alonso, 1964).

Para testar alguns desses argumentos no caso do mercado imobiliário de São Paulo, realizamos uma regressão múltipla, em que a variável dependente era o preço do metro quadrado dos lançamentos imobiliários realizados em São Paulo entre 1985 e 2003. A unidade de análise da regressão era o próprio lançamento imobiliário, sendo que contamos na base de dados com 7.397 registros de lançamentos realizados entre 1985 e $2003 .^{13}$
13 Devido à significativa variabilidade de preços, consideramos como variável dependente o logaritmo neperiano do preço do metro quadrado de lançamento imobiliário. Devido à inflação, os valores nominais foram convertidos para dólares americanos. 
14 Inicialmente foram testadas as distâncias em relação a vários centros de massa, a saber: os quatro centros relacionados aos períodos (1985-1989; 19901994; $1995-1999$ e 20002003); os dois centros de massa relacionados a dois grandes períodos (19851994 e 1995-2003), e, por fim, o centro de massa adotado no modelo, relacionado a todo o período analisado (1985-2003).

15 A fonte de dados original foi o cadastro da RAIS de 2000 geocodificado. Todas as áreas com elevado volume de empregos de alta escolaridade estavam localizadas no Município de São Paulo, nos distritos Itaim Bibi, Vila Mariana, Pinheiros, Consolação, Sé, Santo Amaro, Pari, Barra Funda e República.
16 A variável foi construída a partir da fórmula: \{lárea total do empreendimento/ unidade) - área útil da unidade\}. Inicialmente utilizamos a variável contínua da área útil da unidade residencial. Em seguida, buscamos construir uma variável relacionada ao padrão do imóvel que representasse uma classificação de alto padrão versus restante. Esta variável \{(área útil > $120 \mathrm{~m}^{2} \mathrm{e}$ vagas de garagem $>1$ ) $=1 \mathrm{e}$ restante $=0\}$ também acabou não entrando no modelo, pois optamos por trabaIhar com outra variável que pudesse exprimir o que considerávamos fator "padrão do imóvel": área externa/ lazer.

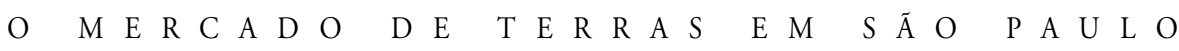

Adotamos diferentes variáveis explicativas (independentes) construídas a partir das referências na literatura mencionadas acima. As variáveis explicativas testadas no modelo foram as seguintes:

- Distância linear de cada lançamento do centro de massa dos lançamentos imobiliários (dist_cmt). Essa distância do centro de massa, calculado para os lançamentos verificados em todo o período de 1985 a 2003, busca captar o efeito da localização do imóvel sobre o preço. Trata-se de uma variável referida ao que poderíamos chamar de "centralidade residencial". ${ }^{14}$

- Distância do imóvel de pólos de empregos de alta escolaridade (dalesc3). Essa variável foi transformada em variável dummy com duas categorias (até $5 \mathrm{~km}$ e mais de $5 \mathrm{~km}$ ). Para tanto, tomou-se a distância do lançamento até o centróide das áreas de ponderação que aglomerassem mais de $2 \%$ do total de empregos de alta escolaridade ( ${ }^{\circ}$ grau completo, superior incompleto e superior completo). ${ }^{15}$ Essa variável foi elaborada de modo a testar a importância dos efeitos de aglomeração, ou o que poderíamos chamar de "centralidade econômica".

- Distância do imóvel de estaçôes de metrô (dmetro2). Também construída enquanto variável dummy, dividida em duas categorias (até $1 \mathrm{~km}$ e mais de $1 \mathrm{~km}$ ). Trata-se de uma variável que testa o impacto do sistema de transportes.

- Distância do imóvel das Zonas Residenciais do tipo Z1 (bandz1). Tais zonas, estritamente residenciais, determinadas no zoneamento municipal, correspondem em geral a áreas de moradia predominantemente de alta renda, onde é vedada a verticalização das construçóes. Em tese, as proximidades das zonas $\mathrm{Z} 1$ tendem a ser valorizadas, tanto por constituírem áreas pouco adensadas, assim como pela idéia de tranqüilidade que oferecem. Dividimos também essa variável em duas categorias: os empreendimentos localizados dentro e fora de um raio de $500 \mathrm{~m}$ de uma $\mathrm{Z1}$.

- Distância do imóvel de praças e parques com mais de $4.000 \mathrm{~m} 2$ (dverde2). Tratadas também enquanto uma variável dummy, consideramos duas categorias (até $1 \mathrm{~km}$ e mais de $1 \mathrm{~km}$ das áreas verdes de grande porte). Trata-se de uma variável relativa às chamadas amenidades ou, na linguagem da economia neoclássica, referida às preferências dos consumidores por certas localizações devido às qualidades que o entorno oferece.

- Distância do imóvel de favelas (dist_fav3). Essa variável, criada a partir da distância do lançamento ao centróide da favela, também foi dividida em duas categorias (até $300 \mathrm{~m}$ e mais de $300 \mathrm{~m}$ de favela). Trata-se de uma variável que dialoga também com a lógica das preferências, com a proximidade, nesse caso, representando um fator negativo.

- Área externa do imóvel (padrao). Essa variável permite uma aproximação com a chamada "área de lazer" de uso comum dos imóveis, dimensão que provavelmente afeta o custo dos empreendimentos e o chamado "padrão" dos imóveis. ${ }^{16}$

- Imóvel do tipo flat (flat). Também inserido como variável dummy (flat ou não), esse tipo de imóvel tem certamente uma dinâmica de valorização diferente dos imóveis residenciais convencionais.

- Período do lançamento, antes e depois do Plano Real (antes_depo). Essa variável buscava captar variações no preço dos imóveis em função de oscilações macro-econômicas mais extremas, como a observada a partir do Plano Real.

$\mathrm{Na}$ prática, diversos modelos alternativos foram avaliados, com variaçōes tanto no que diz respeito às variáveis dependentes consideradas, quanto na forma de construção da 
variável dependente e das independentes. ${ }^{17}$ Para o modelo final, excluímos os lançamentos imobiliários anteriores a 1990, cujos preços apresentavam oscilações muito acentuadas em função das elevadas taxas inflacionárias do período.

O modelo final se mostrou adequado, segundo os parâmetros regulares da análise de regressão (R2 de 68\%). Todas as variáveis do modelo se comportaram do modo esperado. Das nove variáveis consideradas acima, apenas a distância do metrô não foi significativa. Um sumário dos resultados é apresentado na Tabela 1, a seguir.

Tabela 1 - Resultados do Modelo de Regressão Múltipla: coeficientes e significância

\begin{tabular}{|c|c|c|c|c|c|}
\hline \multirow[t]{2}{*}{ Model } & \multicolumn{2}{|c|}{$\begin{array}{l}\text { Unstandardized } \\
\text { Coeficientes }\end{array}$} & \multirow{2}{*}{$\begin{array}{c}\text { Standardized } \\
\text { Coeficientes } \\
\text { Beta } \\
\end{array}$} & \multirow[t]{2}{*}{$\mathrm{t}$} & \multirow[t]{2}{*}{ Sig. } \\
\hline & B & Std. Error & & & \\
\hline 8 (Constant) & 6.747 & 0.026 & & 258.484 & 0.000 \\
\hline dist_cmt & -0.015 & 0.001 & -0.241 & -16.691 & 0.000 \\
\hline flat & 0.414 & 0.025 & 0.172 & 16.285 & 0.000 \\
\hline bandz1 & 0.176 & 0.011 & 0.176 & 15.780 & 0.000 \\
\hline antes_depo & 0.205 & 0.009 & 0.236 & 22.687 & 0.000 \\
\hline padrao & 0.757 & 0.042 & 0.196 & 17.896 & 0.000 \\
\hline dalesc3 & 0.149 & 0.011 & 0.185 & 13.788 & 0.000 \\
\hline dist_fav3 & -0.108 & 0.012 & -0.097 & -9.332 & 0.000 \\
\hline dverde2 & 0.048 & 0.011 & 0.053 & 4.277 & 0.000 \\
\hline
\end{tabular}

a Dependent Variable: In_pre

De modo agregado, esses resultados mostram que os imóveis com preços mais altos por metro quadrado são aqueles mais próximos da chamada "centralidade residencial"; localizam-se em áreas próximas às Z1; foram lançados depois do Plano Real; têm uma área de lazer extensa; ficam próximos dos pólos de emprego de alta escolaridade; estão distantes de favelas e ficam próximos de áreas verdes. Tais resultados convergem com o que foi encontrado, por exemplo, no estudo de Hermann e Hadad (2005), que estima os preços implícitos das amenidades urbanas no MSP. ${ }^{18}$ Os imóveis do tipo flat também têm um valor mais elevado.

O resíduo não explicado pelo modelo (32\%) pode ser possivelmente referido a fatores micro locacionais não considerados entre as variáveis aqui apresentadas, como, por exemplo, a localização do imóvel em avenidas movimentadas e a circulação de ônibus na rua do imóvel. Esses elementos não foram considerados por falta de dados. Outros aspectos relacionados às características do imóvel também não puderam ser testados, tais como o número de garagens, as características construtivas do imóvel (estilo arquitetônico, tipo de material empregado etc).

De modo resumido, esses resultados sugerem que a formação do preço dos imóveis residenciais é um fenômeno relativamente complexo, atribuído a diferentes aspectos relativamente heterogêneos, tais como: a distância da centralidade, a proximidade de amenidades, o padrão construtivo etc. Cabe, porém, destacar que no caso da Região Metropolitana de São Paulo, a variável mais importante para esse modelo é a distância do centro de massa (dist_cmt), sendo este entendido como centralidade residencial, que explica isoladamente $49 \%$ da variabilidade observada. Esse resultado pode ser observado na Tabela 2, a seguir.
17 Para mais informações sobre como as variáveis independentes foram construídas, ver o Anexo.
18 Os autores constataram que "a presença de (...) áreas verdes e zonas estritamente residenciais contribuem para a elevação do preço (...). A baixa significância das estacõos de metrô e da atividade comercial pode ser duplamente explicada pela forte multicolinearidade das variáveis que compõem o vetor e pelo próprio efeito ambíguo dos fenômenos, que contribuem ao mesmo tempo positiva e negativamente para a valorização dos imóveis. (...) 0 modelo (...) revela a implicação da oferta de infra-estrutura urbana sobre a moradia, o que leva à conclusão de que as regiões mais centralizadas apresentam valores proporcionalmente mais elevados". (Hermann e Hadad, 2005). 
Tabela 2 - Resultados do Modelo de Regressão Múltipla: R2

\begin{tabular}{llr}
\hline Variável & & R2 \\
\hline dist_cmt & Distância do centro de massa & $48,88 \%$ \\
flat & Imóvel tipo flat & $5,96 \%$ \\
bandz1 & Proximidade de Zonas Exclusivamente Residenciais & $4,05 \%$ \\
antes_depo & Lançamento ocorrido antes e depois do Plano Real & $3,45 \%$ \\
padrao & Indicador de área externa do imóvel & $3,43 \%$ \\
dalesc3 & Proximidade a pólo de emprego de alta escolaridade & $1,55 \%$ \\
dist_fav3 & Distância de favelas & $0,64 \%$ \\
dverde2 & Distância de áreas verdes & $0,14 \%$ \\
\hline Total & & $68,10 \%$ \\
\hline
\end{tabular}

Tal resultado indica que a ênfase colocada na literatura brasileira a respeito do impacto da localização da moradia de alta renda para a formação do gradiente do preço da terra urbana é bastante correta, embora, como é possível constatar, outros fatores também concorram para a formação do preço. A não inclusão da variável relacionada à proximidade ao sistema de transporte (metrô) não indica necessariamente a irrelevância da dimensão transportes. A não relevância dessa variável está possivelmente associada às limitações do sistema de metrô na cidade, inclusive por não chegar ao setor sudoeste, onde o preço da terra é mais elevado.

Em vista da importância da variável de distância do centro de massa, vale a pena discutir a evolução temporal da relação entre preço e distância da centralidade. A rigor, se o adicional de preço pago pela centralidade cair ao longo do tempo, a pressão pela expansão periférica será menor, uma vez que grupos de renda intermediária poderiam passar a residir em áreas anteriormente inacessíveis. Se, ao contrário, o adicional de preço pago pela centralidade aumentar ao longo do tempo, as áreas centrais se tornariam ainda mais "exclusivas". Exploramos essa dinâmica na próxima seção.

\section{EVOLUÇÃO TEMPORAL DA RELAÇÃO PREÇO DOS LANÇAMENTOS E DISTÂNCIA DA CENTRALIDADE}

Ao longo da década de 1990, o preço dos lançamentos imobiliários cresceu substancialmente nas áreas mais próximas à centralidade urbana; enquanto, no período entre 1990-1994, os preços dos lançamentos imobiliários nas áreas mais centrais da cidade aquelas mais próximas do centro de massa considerado - custavam aproximadamente um mil e setecentos dólares americanos o metro quadrado. No período entre 2000-2003, esse preço tinha crescido para, aproximadamente, dois mil e quinhentos dólares. Trata-se de um aumento médio superior a 50\%. Esses resultados são apresentados no Gráfico 1. 
Gráfico 1 - Relação entre preço do $\mathrm{m}^{2}$ de lançamento residencial e distância do centro de massa. RMSP, 1990-2003

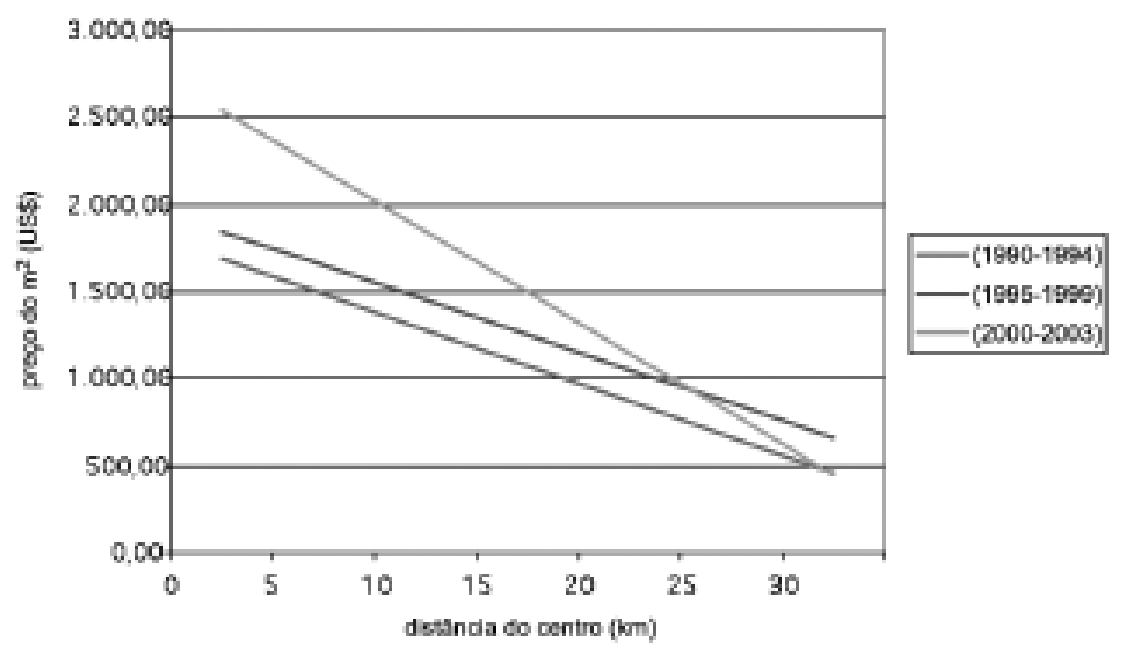

Fonte: Elaboração a partir de dados da Embraesp.

As curvas apresentadas nesse Gráfico 1 são fruto de regressões simples entre o preço do metro quadrado do lançamento e a distância do centro de massa. Consideramos aqui três períodos distintos: 1990-1994, 1995-1999 e 2000-2003. ${ }^{20}$ Por meio desse gráfico, podemos observar também que a o diferencial entre o preço do metro quadrado próximo à centralidade e aquele localizado a $25 \mathrm{~km}$ da centralidade, por exemplo, cresceu substancialmente. Enquanto no primeiro período um imóvel próximo ao centro de massa tinha um preço por metro quadrado 2,5 vezes superior ao preço de um lançamento localizado a $25 \mathrm{~km}$ desse centro, no período 2000-2003, esse diferencial tinha crescido para 3,2 vezes. Esse resultado é, sem dúvida, inquietante, e sugere que as áreas centrais estão se tornando, no âmbito do mercado residencial formal de terras, mais restritivas à localização de grupos de renda intermediária ou baixa. ${ }^{21}$

Em outras palavras, para além do aspecto discutido anteriormente, relacionado ao gradiente do preço em função da localização do imóvel, constata-se que os preços do solo urbano continuam aumentando nos últimos quinze anos, sobretudo nas áreas mais centrais da metrópole. Esse aumento excessivo e constante de preços da terra nas áreas mais centrais tem conseqüências diretas para a estruturação urbana e especialmente no que diz respeito ao acesso a terra no mercado formal.

É importante ressaltar que, não por acaso, o volume de lançamentos imobiliários nas áreas mais centrais de São Paulo foi acompanhado de um significativo decréscimo populacional dessas áreas mais consolidadas (Torres, 2005). Aparentemente, também se pode dizer que esse aumento contínuo tem contribuído para a ocorrência de um processo já descrito na literatura como "gentrificação", caracterizado, em termos gerais, por uma dinâmica de expulsão de moradores que pertencem a classes sociais menos favorecidas de certas áreas urbanas, comumente em decorrência de valorização imobiliária dessas áreas. Ocorre, assim, um processo de troca populacional, em que os mais pobres não podem mais se manter no local, que passa a ser ocupado por camadas de renda intermediária ou mais elevadas (Smith, 1996; Arantes, 2000). No caso de São Paulo, apesar da maior verticalização, a população de diferentes bairros do centro-expandido tem diminuído (Tor-
$19 \mathrm{P}=\mathrm{ax}+\mathrm{B}$ (onde: $\mathrm{P}=$ preço do metro quadrado (em dólar); ax = distância teórica $\mathrm{x}$ coeficiente $\mathrm{da}$ regressão, e $\mathrm{B}=$ constante).

20 Nos três casos, o R2 das regressões simples foi superior a $48 \%$.

21 Não por acaso, os indicadores de segregação residencial mostram que a segregação aumentou na década passada em São Paulo (Torres, 2004). 
res, 2005; Villaça, 1998). Esse é o caso de bairros como Pinheiros, Vila Mariana, Perdizes, Vila Madalena, Aclimação, Vila Olímpia, Brooklin e Pompéia.

Evidentemente, essa lógica de valorização sistemática dos ativos imobiliários nas áreas mais nobres da cidade tem impactos substanciais para toda a dinâmica urbana, uma vez que menos moradores terão acesso a essas áreas. Como conseqüência, um grupo maior de famílias terá que buscar as áreas mais distantes como alternativa de moradia. Analogamente, na ausência de um mercado formal de moradias acessível para os grupos de menor renda e de políticas públicas de provisão habitacional eficazes, mais pessoas terão que residir em áreas irregulares, como favelas e loteamentos clandestinos. Não por acaso, as taxas de crescimento demográfico em áreas periféricas e em favelas e loteamentos clandestinos e/ou irregulares, em geral caracterizados pela precariedade habitacional e pela situação de irregularidade fundiária, foram muito superiores à média da Região Metropolitana entre 1991 e 2000 (HABI/PMSP, 2004).

Embora não seja o caso, no âmbito desse artigo, analisar exaustivamente as razões associadas ao aumento do preço da terra nas áreas urbanas mais próximas à centralidade, vale a pena aqui formular algumas hipóteses principais:

- O ambicioso projeto, em curso há várias gestôes municipais, de ampliação do sistema viário no setor sudoeste, particularmente nos eixos das avenidas Juscelino Kubitschek, Engenheiro Luis Carlos Berrini e Roberto Marinho - acompanhado por remoções de favelas e mudanças no padrão do uso do solo - implicou, provavelmente, em aumento do preço da terra em áreas onde a valorização imobiliária já era elevada.

- A estagnação do investimento no sistema de transporte público ao longo da década de 1990, particularmente na expansão do metrô, acompanhada do aumento dos congestionamentos, possivelmente implicou em aumento do custo efetivo do transporte de áreas mais distantes da centralidade. Nesse sentido, é possível que a moradia em locais próximos ao trabalho tenha se tornado um elemento ainda mais valorizado do que anteriormente.

- A estabilização econômica, num cenário de ausência de financiamento imobiliário adequado, aparentemente implicou em especialização de boa parte do setor imobiliário no chamado mercado de "alto padrão". A baixa capacidade de poupança e a ausência de financiamento adequado para casa própria em função das elevadas taxas de juros contribuem para o estancamento da produção imobiliária para a classe média.

Infelizmente, não temos condições de apresentar, nesse artigo, subsídios mais palpáveis a respeito da validade dessas hipóteses. De todo modo, discutimos alguns significados desses resultados do ponto de vista de políticas públicas na próxima seção.

\section{CONSIDERAÇÕES FINAIS}

Como apresentado, o presente artigo foi elaborado em torno de três perspectivas principais. Inicialmente, buscamos definir um conceito operacional de centralidade. A partir do indicador de centro de massa do preço dos lançamentos imobiliários, pudemos observar que, embora esses lançamentos estivessem se espraiando mais, a centralidade residencial variou pouco na metrópole paulistana nos últimos anos, localizada em uma região consolidada, dotada de infra-estrutura, serviços e sistemas de transportes (Seção 1). 
Em segundo lugar, buscamos operacionalizar um modelo que refletisse a formação do preço dos novos lançamentos imobiliários no mercado formal de terras. Embora um conjunto diversificado de elementos convergisse para a formação desse preço, a variável distância da centralidade residencial mostrou-se como sendo a mais relevante (Seção 2). Esse resultado confirma vários argumentos presentes na literatura urbana brasileira.

Em terceiro lugar, buscamos avaliar como se deu a evolução da relação entre preço da terra e distância da centralidade nos últimos quinze anos (Seção 3). Os dados levantados apontam para um substancial incremento do preço médio do metro quadrado de lançamento residencial nas áreas mais próximas da centralidade. Trata-se de um resultado surpreendente, ainda não observado na literatura, com extensas conseqüências para a vida urbana.

Ressalta-se que, a rigor, a lógica de valorização sistemática dos ativos imobiliários nas áreas mais ricas da cidade tem impactos significativos na estruturação e dinâmica urbanas. A principal consequiência resulta que - na ausência de processos substanciais de melhoria na distribuição da renda - um número menor de moradores tem acesso ao chamado "centro expandido". Isso também contribui para que um número maior de pessoas tenha que buscar as periferias e favelas como alternativa de moradia. Nesse sentido, a discussão sobre políticas públicas capazes de reverter essas tendências de valorização tem importância fundamental sobre o acesso a terra e qualidade de vida urbana.

Desse modo, vale a pena refletir, ainda que brevemente, sobre alternativas de gestão e de políticas públicas que pudessem contrastar essa tendência de aumento do preço da terra nas áreas urbanas mais próximas da centralidade. Em primeiro lugar, o poder municipal poderia descentralizar mais fortemente o investimento público. $\mathrm{O}$ investimento em infra-estrutura urbana tem se concentrado muito em regiōes já consolidadas, sobretudo no chamado vetor sudoeste, sendo que, até onde sabemos, essa prática foi particularmente importante nos governos Jânio Quadros, Paulo Maluf e Celso Pitta (Marques, 2003). Muito provavelmente, tais investimentos têm impactos substanciais sobre a valorização da terra urbana.

Em segundo lugar, o governo estadual precisa retomar a ampliação do sistema de metrô. Nesse sentido, o recente lançamento da Linha 4 parece auspicioso, porque permitiria integrar ao sistema uma maior fração da região oeste da RMSP. Embora gerando valorização das áreas diretamente beneficiadas, isso poderá ter impactos sobre os custos de transporte e os tempos de deslocamento, reduzindo, de certo modo, a importância relativa da moradia em locais mais próximos da centralidade.

Finalmente, existem também outras possíveis ações do setor público no sentido de regular o gradiente de preços da terra urbana. Tais práticas decorrem de uma ação mais incisiva e inclusiva do Estado, e podem envolver açōes como a taxação progressiva dos imóveis subutilizados em áreas consolidadas, a contribuição de melhorias, a delimitação de Zonas Especiais de Interesse Social (ZEIS) e a flexibilização dos parâmetros de uso do solo nas zonas mais restritivas, como a Zonas Exclusivamente Residenciais. É de fundamental importância a efetiva aplicação de instrumentos de regulação do mercado do solo que possibilitem maior acessibilidade ao solo urbano barato, seguro e dotado de infraestrutura.
Haroldo da Gama Torres é economista, mestre em demografia e doutor em Ciências Sociais pela Unicamp. Pesquisador sênior do Cebrap e membro do Conselho Curador da Fundação Seade.

E-mail: hgtorres@uol.com.br

Renata Gonçalves é arquiteta, mestre em administração pública pela FGV e pesquisadora associada ao Centro de Estudos da Metrópole (CEM) - Cebrap.

E-mail: rerochagon@uol. com.br

Artigo recebido em abril de 2008 e aprovado para publicação em outubro de 2008. 


\section{REFERÊNCIAS BIBLIOGRÁFICAS}

ABRAMO, P. Le marché, l'ordre-désordre et la coordination spatiale. Paris, E.H.E.S.S., Tese de Doutoramento, 1994.

ALONSO, W. Location and land use. Harvard University Press, Cambridge, Massachusetts, 1964.

ARANTES, O. F. Uma Estratégia Fatal: a cultura nas novas gestóes urbanas. In: ARANTES, O.; VAINER, C. B. e MARICATO, E. A cidade do pensamento único: desmanchando consensos. Petrópolis: Vozes, 2000.

BIDERMAN, C. Forças de atração e expulsão na Grande São Paulo. São Paulo, FGV SP, Tese de Doutoramento, 2001.

BONDUKI, N.; ROLNIK, R. Periferia da Grande São Paulo: reprodução do espaço como expediente de reprodução da força de trabalho. In: MARICATO, E. (org.) $A$ produção capitalista da casa (e da cidade) do Brasil industrial. São Paulo: Alfa-Ômega, 1982.

FRÚGOLI JR., H. Centralidade em São Paulo: trajetórias, conflitos e negociações na metrópole. São Paulo: Cortez; Edusp, 2000.

HABI/PMSP. Plano Municipal de Habitação da Cidade de São Paulo. São Paulo: mimeo, 2004.

HENDERSON, J.V. Urban development: theory, fact and illusion. New York: Oxford University Press, 1988.

HERMANN, B. M.; HADAD, E. A. Mercado Imobiliário e Amenidades Urbanas: A View Through the Window. Estudos Econômicos, São Paulo, 35(2): 237-69, abr-jun 2005. MARICATO, E. Metrópole na periferia do capitalismo: ilegalidade, desigualdade e violência. São Paulo: Hucitec, 1996.

. Habitação e Cidade. São Paulo: Atual (série Espaço \& Debate), 79 p., 1997. Brasil, cidades: alternativas para a crise urbana. Petrópolis: Vozes, 2001. Metrópole, legislação e desigualdade. Estudos Avançados, maio/ago, 2003, vol.17, n.48, pp.151-66. ISSN 0103-4014.

MARQUES, E. A dinâmica imobiliária de incorporação no período recente. In: MARQUES, E.; TORRES, H. (org.) São Paulo: segregação, pobreza urbana e desigualdade social. São Paulo: Editora Senac, pp. 213-41, 2005.

Redes Sociais, Instituiçôes e Atores Políticos no Governo da Cidade de São Paulo. São Paulo: Annablume Editora, 2003.

; BITAR, S. Espaço e grupos sociais na metrópole paulistana. Novos Estudos Cebrap, n.64. 2002.

; BICHIR, R. Investimentos públicos, infra-estrutura urbana e produção da periferia em São Paulo. Revista Espaço e Debates, n.42, 2002.

; TORRES, H.; SARAIVA, C. Favelas no Município de São Paulo: estimando a sua presença para os anos de 1991, 1996 e 2000. Revista Brasileira de Estudos Urbanos, vol.5, n.1, 2003.

NERI, J. Um século de politica para poucos: o zoneamento paulistano 1886/1996. São Paulo: FAU/USP, Tese de Doutoramento, 2002.

RIBEIRO, L. Dos cortiços aos condomínios fechados: as formas de produção da moradia na cidade do Rio de Janeiro. Rio de Janeiro: Civilização Brasileira, 1997.

RICHARDSON, H. W. Urban Economics. Harmondsworth: Penguin, 1971.

ROLNIK, R. A cidade e a lei: legislação, política urbana e territórios na cidade de São Paulo. São Paulo: Nobel/Fapesp, 1997. 
SARAIVA, C.; MARQUES, E. A condição social dos habitantes de Favelas. In: MARQUES, E.; TORRES, H. (Org.). São Paulo: segregação, pobreza urbana e desigualdades sociais. São Paulo: Senac, pp.143-67, 2005.

SMOLKA, M. Para uma reflexão sobre o processo de estruturação interna das cidades brasileiras: o caso do Rio de Janeiro. Espaço e Debates, n.21, 1987.

. Expulsando os pobres e redistribuindo os ricos: "dinâmica imobiliária" e segregação residencial na cidade do Rio de Janeiro. Revista Brasileira de Estudos Populacionais. Campinas, vol.9(1), 1992.

SMITH, N. The new urban frontier: gentrification and the revanchist city. New York: Routledge, 1996.

TORRES, H. da G. A fronteira paulistana. In: MARQUES, E.; TORRES, H.G. (orgs.). São Paulo: segregação, pobreza e desigualdade. São Paulo: Editora do Senac, pp.101-20, 2005.

. Segregação residencial e políticas públicas: São Paulo na década de 1990.

Revista Brasileira de Ciências Sociais, vol.19, n.54, pp.41-56, 2004.

. ; MARQUES, E. Políticas Sociais e Território: Uma Abordagem Metropolitana. Revista São Paulo em Perspectiva, vol.18, n.4, 2004.

VALLADARES, L.; COELHO, M. Pobreza urbana e mercado de trabalho: uma análise bibliográfica. O que se deve ler em ciências sociais no Brasil, n.2. São Paulo: Anpocs/Cortez, 1987.

VETTER, D. The impact on the metropolitan system of the interpersonal and spatial distribution of real and monetary income: the case of Grande Rio. Comparative Urbanization Series. University of California, Los Angeles, 1975.

. ; PINTO, D.; FRIEDRICH, O.; MASSENA, R. A apropriação dos bene-

fícios das ações do Estado em áreas urbanas: seus determinantes e análise através da ecologia fatorial. Espaço e Debates, vol.1(4), 1981.

.; MASSENA, R. Quem se apropria dos benefícios líquidos dos investimentos do Estado em infra-estrutura? Uma teoria da causação circular. In: SILVA, L.A.M. da (org). Solo urbano - Tópicos sobre o uso da terra. Série Debates Urbanos. Rio de Janeiro: Zahar Ed, 1981.

VILLAÇA, F. Espaço intra-urbano no Brasil. São Paulo: Fapesp/Lincoln Institute/Nobel, 1998.

\section{ANEXO}

Quase todas as variáveis utilizadas na análise de regressão foram construídas a partir de um Sistema de Informações Geográficas. O Mapa 4 a seguir mostra os principais elementos geográficos (áreas verdes, estaçōes de metrô, pólos de emprego etc.) utilizados para construção das variáveis independentes na análise de regressão apresentada na Seção 2. 
Mapa 4 - Entidades geográficas utilizadas para construção de variáveis independentes utilizadas na regressão

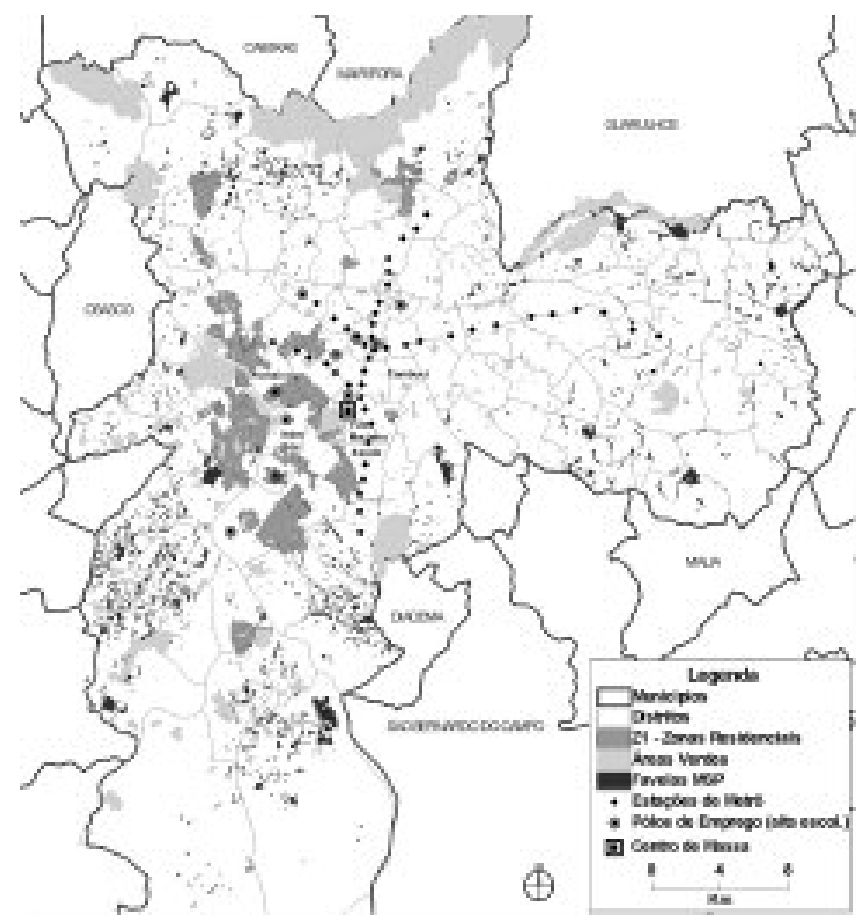

Fonte: Bases cartográficas disponíveis no Centro de Estudos da Metrópole/ Cebrap, elaboradas a partir de diversas fontes.

A B S T R A C T This article analyzes how the formal real estate production of the Metropolitan Area of São Paulo has evolved in the past 15 years. From a brief discussion on the idea of centrality, and by using real estate data on new developments (Embraesp), the authors have produced a pricing model that stresses the importance geographic location plays in determining real estate prices. Data also indicate that prices of residential real estate substantially increased during the 1990s in more central urban areas. This may partly explain why the so-called "expanded central area" has been experiencing a process of demographic decline, while peripheral areas have consistently swollen: a limited number of city dwellers can afford living in the more valuable central areas.

K E Y W O R D S Land market; residential segregation; São Paulo; urban planning; metropolitan areas. 